\title{
Vegetation protection and road landscape construction technology along the Yunmao expressway
}

\author{
Jian Lou ${ }^{1}$, Siqing Zeng ${ }^{2 *}$, Min $\mathrm{Cai}^{3}$, Tianwen Liang ${ }^{4}$, Dan Wang ${ }^{5}$ and $\mathrm{Ke} \mathrm{Yao}^{6}$ \\ 1,2,3 Yun Mao Expressway, Guangzhou, Guangdong Province, 510623, China \\ ${ }^{4,5}$ Research Institute of Highway Ministry of Transport, Beijing, 100086, China \\ ${ }^{6}$ Guangdong Provincial Transportation Planning Research Center, Guangzhou, Guangdong Province, 510101, China
}

\begin{abstract}
The construction of green highways must not only combine the characteristics of regional ecological environment, but also do a good job of landscape greening to create a good driving environment. Taking Yunmao expressway as an example, from the perspective of ecological protection and restoration, this paper describes the design ideas of vegetation protection and landscape construction along the expressway, and discusses the landscape greening design of expressways characteristic of Guangdong Province based on the actual experience of landscape greening of expressways in Guangdong Province.
\end{abstract}

\section{Introduction}

Expressway landscape greening refers to the restoration of the damaged ecological environment around the expressway, the use of vegetation roots and stems to consolidate the soil and improve the soil's corrosion resistance, so as to strengthen the slope, this can not only improve the landscape environment around the highway, but also play a role in reducing noise and road temperature.With the improvement of people's material culture and spiritual civilization, the technology level of expressway landscape construction is also getting higher and higher. How to reduce the highway to the greatest extent has become the starting point and the fundamental point of highway landscape construction. The destruction of the environment makes the highway more harmoniously integrated into the natural environment.

\section{Overview of the study region}

\subsection{Project Overview}

The Yunmao Expressway is the link between the "Nine Longitudinal Lines" of Luoyang Expressway and the " 10 Longitudinal Lines" of Baomao National Expressway planned by the Provincial Expressway Network. The Beiliu (Qingwan) Expressway is an economic trunk line leading to the Pearl River Delta from the western Guangdong mountainous region and the northern part of Northern Gulf. The route runs from east to west through Luoding, Xinyi and Gaozhou, with a total length of $129.816 \mathrm{~km}$. Yunmao Expressway passes through 3 ecological and environmentally sensitive areas. It is located in a mountainous and heavy hilly area. The longitudinal slope of the line is undulating, and there are many long uphill and long downhill sections. Special liquid soils such as high-liquid limit soil and soft soil are dense, and bad geology such as collapse and karst are more common, which is a typical mountain highway.

\subsection{Environmental Overview}

2.2.1. Overview of the natural environment. The Yunmao Expressway is located in the Yunkai mountains, west of the Yunwu mountains. The survey area is generally high in the west and low in the east. It is dominated by low and medium mountains and hilly terrain. It belongs to the south subtropical monsoon climate, but has the characteristics of complicated and changeable mountain climate. The summer is long without severe winter, the temperature is high, and the average annual temperature is $22.1{ }^{\circ} \mathrm{C}$.

2.2.2. Overview of the ecological environment. During the route selection phase of the proposed project, it actively avoided ecologically sensitive areas, such as nature reserves, forest parks, strict ecological control areas and drinking water source protection areas. The currently recommended scheme spans the Huanghua River in Xinyi City and the aquatic resources county-level nature reserve (K53 + 470 $\sim \mathrm{K} 80+450$ cross-river bridge), but there is no water pier, and the protected area is not occupied by ecologically sensitive areas including Xiabao County Nature Reserve, Xinyi City (the project avoids the protected area, $\mathrm{K} 82 \sim \mathrm{K} 83$ is closest to the protected area about $180 \mathrm{~m}$ ) and Guangdong Province ecological control Zone area (the project avoids the strictly controlled area, $\mathrm{K} 63+100 \sim \mathrm{K} 63+250$ The closest distance to the strictly controlled area is about $50 \mathrm{~m}$. 
The construction of expressways in the above ecologically sensitive areas will inevitably cause disturbance and damage to the ecosystems in sensitive areas, affecting ecological services such as water, soil and water conservation, landscape recreation, and biodiversity protection. Management and control measures for ecological and environmental protection must be strengthened to protect green water and green mountains to the greatest extent.

\section{Transplantation and reuse techniques of natural trees}

In order to fully protect and utilize the abundant nature nursery stock resources of the Yunmao Expressway and implement the concept of ecological environment protection, during the initial land acquisition cleanup work, the nature applicablenursery stock were protected and transplanted. According to previous surveys, the tree species surveyed are mainly Caphura lignum pineapple, mango, oliva, nigrum oliva, litchi, longan, mons Yung, kapok alia formosa, PRUNUM, mainly distributed online, interoperability and appendage Within the area of the housing construction facility station, the nursery stock transplantation storage site was temporarily forged in the management center area and applied to the Yunmao Highway landscape greening project after the temporary transplantation protection base was maintained. The site covers more than 60 acres and has more than 2,300 trees of more than 20 species of plants.

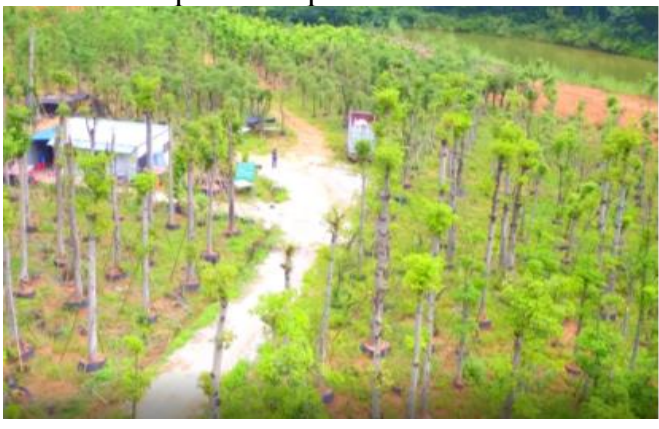

Figure 1. Fake planting of nursery stock

\section{Technical countermeasures for highway landscape construction}

\subsection{Design Concept}

The highway landscape construction technology adheres to the people-oriented design concept, takes highway environmental protection as the basic starting point, and abandons the habit of "destroying first, then recovers" to synchronize project construction with environmental restoration. Based on the principles of landscape ecology, select tree species to adapt to local conditions, combine arbor and grass, unified layout and reasonable mix, use the greening and landscaping functions of vegetation, improve road appearance, optimize driving environment, and exert comprehensive anti-glare benefits, To mitigate accidents and disasters, thereby achieving the purpose of safe operation, and building the Yunmao Expressway into a safe and beautifying ecological road.

\subsection{Landscape design methods for keyareas}

4.2.1. Close-to-nature ecological slope protection. The Close-to-nature ecological slope protection technology is to maximize the restoration of the natural landscape. The conventional knife-cut excavation mode is changed to simulate the shape of the original mountain body. The slope is streamlined and trimmed. The slope and preexcavation. The morphology of the mountain is basically consistent, and landscape ecological restoration and vegetation restoration are implemented.

The choice of species is mainly based on shrubs, and the variety is as diverse as possible, which improves the stability and resistance of plant communities and enhances the expressive power of the Yunmao Expressway landscape. Ground cover plants and flowering shrubs, such as Silvestris Chrysanthemum purpura primum traheretur Cicer, Cassia Yunnan Huang Xin, Hypericum, Viburnum, Pyracantha aurea privet equos spinam multiflora. When the flowering season arrives, the scenery is very beautiful. At the same time, we must pay attention to the amount of fallen leaves of the plants, not to be too large, so as not to affect the driving safety of the highway during the fallen leaves season.

4.2.2. The design of ecological side ditch. In accordance with the requirements of the Letter on the Use of Green Ecological Drainage System Design Guidelines for Highway Engineering in Guangdong Province (Yuejiao Regulation Research Letter [2018] No. 12), Yunmao Company sorted out that the construction drawings of the project adopt the BG-A shallow dish type, with a section Dimensions (width* height) $260 * 45 \mathrm{~cm}$, total length $15176.4 \mathrm{~m}$ 


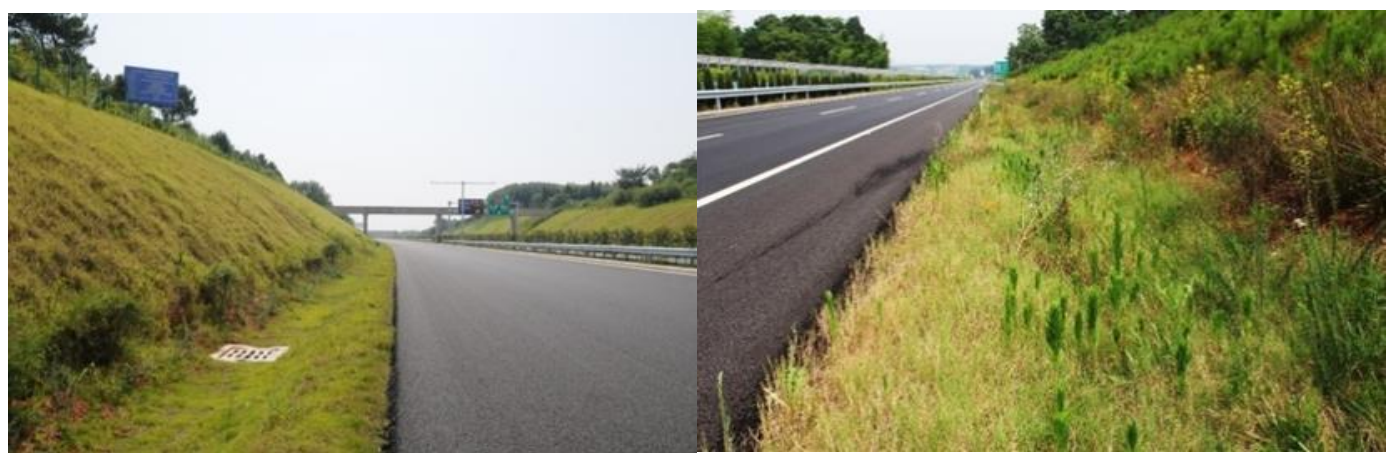

Figure 2. Photo of ecological side trench system technology application case

4.2.3. Greening of Interchange Area. In order to ensure the safety of traffic, the internal confluence area is planted with small flowering trees and shrubs without obstructing the sight of the traffic; the flowering small trees are mainly used in the diversion area; the evergreen large trees are partially dotted with the ramp enclosing area to form the intersection of sight lines. The sight of the plants under the interchange ramp is generally out of reach, so deciduous large trees or sack-planted trees are planted; large bridges and small flowering trees are planted at the abutment while they are sheltered. The main plants are: Hong Yin, arbores autumnales, kapok, firepower, nan, Poinciana subridens Sylvestrial, Ziwei denique foliis, Huang Huaiand so on.

4.2.4. Greening of central partition. The mid-strip greening is used as a full-line functional base, mainly to meet the anti-glare function, supplemented by ornamental, and focuses on the role of safety prompts. The overall arrangement of greening is mainly based on the shrubtype greening mode, with evergreen as the main tone, and with adaptable, long flowering and colorful flowering shrubs to alleviate the visual fatigue that the monotonous landscape may bring to the crew, Improve driving safety and enhance landscaping effect. Ecologically pay attention to the application of local indigenous plants and ground cover plants to achieve multi-level planting as far as possible; pay attention to the use of high ornamental value plant species in the landscape; pay attention to the variety of height and color combinations. At the same time, it is required to have lush foliage, evergreen, and good shading.

Based on the characteristics of the Yunmao Expressway and the environmental conditions of the area, Huang Rong pilas and lignea sphaera Rubri were selected as anti-glare plants in the middle zone, and planted at $3 \mathrm{~m}$ intervals.

4.2.5. Highway roadside greening. The plant design on both sides of the route is to better guide the sight, ensure safety, and take into account the landscape effect. Roadside greening planting should break the traditional rigid tree-type planting method of the road, and fully combine the landscape environment on both sides of the road. The planting method is mainly based on permeability, supplemented by functional planting such as shielding and guidance. Combining the characteristics of the surrounding environment of the Yunmao Expressway, the highway's own landscape is integrated with the natural landscape on both sides, and the unique natural scenery along the highway is fully displayed.

The roadside greening interface is planted with broken platforms for planting and greening, excluding soil road shoulders and slope protection. The plants are mainly planted with acacia chinensis and bougainvillea balls at $4 \mathrm{~m}$ intervals to create roadside landscapes.

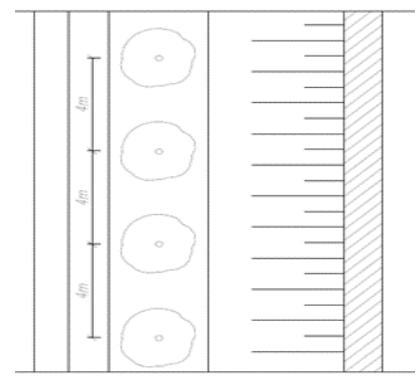

Figure 3. Planting and greening design of broken platform

4.2.6. Greening of tunnel entrances and exits. There are 8 tunnels on the Yunmao Expressway. In order to create a pleasant and natural ecological tunnel opening landscape, the coordination between the tunnel opening and the environment should be fully considered in the design. The goal is to create a natural opening, and to emphasize the visual comfort of the tunnel traffic and improve Driving safety. Drivers need to withstand the change of space and light when entering and exiting the tunnel. The greening of the gradual section of the tunnel plays an important role in inducing the driver's sight. When designing the split 
subgrade in the tunnel entrance, the brightness difference between the inside and outside of the tunnel door needs to be combined, and it is designed to plant denser plants when entering the tunnel to achieve the effect of entering the tunnel in advance. The principle is to achieve the effect of exiting the hole in advance, so as to reduce the impact of brightness differences on the driver's driving sight and ensure driving safety. Based on its width, the narrow subgrade at the entrance of the tunnel is narrow to the right, and low to high plants are used to plant trees and shrubs. At the same time, the use of group planting is supplemented by flowering small trees to form landscape highlights. The main plants used in the greening of the Yunmao Expressway Tunnel are: Hong Yin, Bauhinia rosea in palatio comedimus, Quang Ninh tea, bicapsularis, Pompon leguntur and griseo Li.

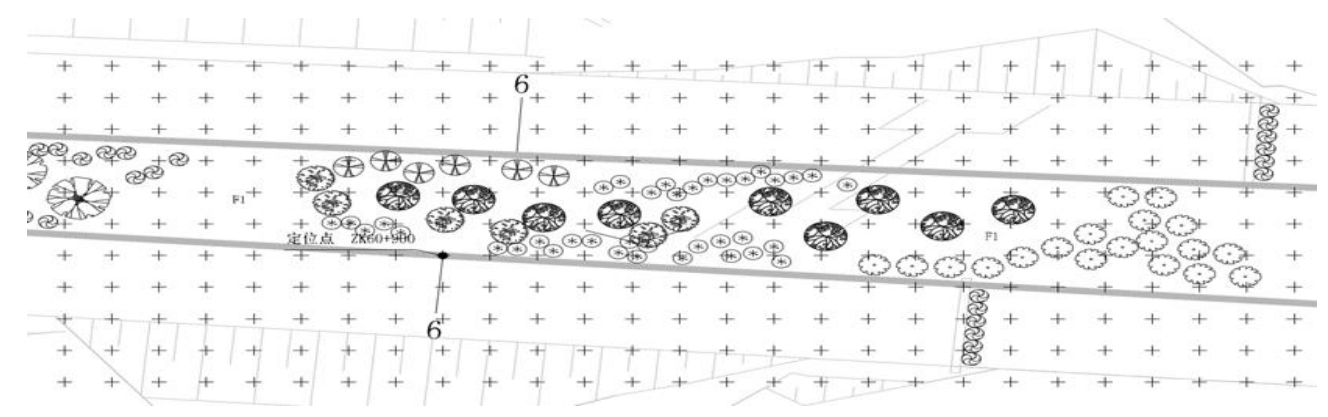

Figure 4. Greening Design of Tunnel Entrance and Exit Area

\section{Conclusion}

As a new concept and new trend of highway construction and development, green highway has become a key area for the development of green transportation and an important symbol for the construction of a beautiful China. Landscape greening as a means can prevent soil erosion, carbon and dust reduction, and protect the environment. It can also beautify the scenery and provide good driving conditions for the driver. Yunmao Expressway combined with the ecological environment conditions, and tried to follow the green concept in the entire process from highway planning and design to engineering construction. It implemented the exploration and practice of tree transplantation protection and utilization, road ecological restoration, and landscape construction technology for environmental protection and ecological restoration in Guangdong made a good demonstration.

\section{References}

1. Qin, X.C., Shen, Y., Shao, S.G., et al.(2010). Discussion on key technology and application of green highway construction under low carbon concept. Highway Transportation Technology [J].(application technology edition) (10):316$318+330$

2. Wu, Q.Y., Xu, J.P., Gao, C.Q., et al.(2006).Technical Guidelines for Coronary Artery Bypass Grafting [J] .Chinese Journal of Surgery, 22:1517-1524.

3. Wang, D., Yan, X.L., Qin, X.C.(2009). Discussion on the Status and Development Trend of Highway Landscape Design [C] .National Highway Ecological Greening Theory and Technology Symposium.Bejing.17-19.

4. Liu, Y.B., Jiang, Y., Gu, W., et al.(2007) Study on evaluation of surface soil protection effect of vegetation slope protection in road area [J].Highway Transportation Science and Technology (Application
Technology Edition).03: 45-49.

5. Yan, X.L., Gu, W, Jiang, Y., et al.(2007).Study on the systematic design of the application of highway ecological engineering technology $[\mathrm{J}]$.Highway Transportation Science andTechnology.07:153-158.

6. Qin, X.C., Shen, Y., Shao, Z.G., et al.(2010).Discussion on key technology and application of green highway construction under low carbon concept $[\mathrm{J}]$.Highway Transportation Science and Technology (Application Technology Edition).10: 316-318+330.

7. Qin, X.C., Zhang, X.N., Guan, C.Y., et al.(2006). Highway landscape and observation deck design [J] .Chinese and Foreign Highway.04: 24-26.

8. Su, Q.H., Ma, J.R., (2016).Study on landscape planning and reconstruction countermeasures of expressway service area [J].Highway Transportation Technology (Application Technology Edition), 12(07):244-246.

9. Chen, D.H., Ma, J.R., Lu, Y.(2015).Research on highway tunnel landscape design technology [J].Highway Transportation Science and Technology (Application Technology Edition).10:137-138+144.

10. Ma, J.R., Wang, D., Sun, C., et al.(2014). New concepts in reconstruction of highway ecological landscape forest corridor [J].Transportation Construction and Management.22: 25-28.

11. Ma, J.R., Wang, W.G., Wang, D.(2014). Study on adaptability of vegetation planting technology on expressway slope [J]. Highway Transportation Science and Technology.12:428-431. 